\title{
JOURNAL_RU
}

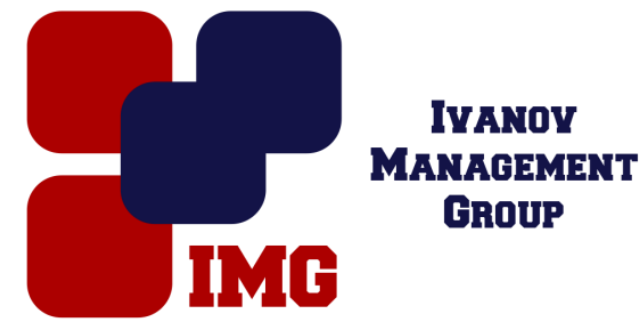

Рагимова А.Р., Исмаилов 3.И., Гусейнова Г.А., Шукюрова Г.М., .Джафарова Е.К., Султанова С.Г. Бакинский Государственный Университет Баку, Азербайджан

doi: 10.18411/spc-31-07-2017-01

idsp 000001:spc-31-07-2017-01

\section{Синтез комплексов двухвалентного меди и никеля с Шиффовым основанием}

\section{Аннотация}

Осуществлен синтез комплексов двухвалентного меди и никеля с Шиффовым основанием, полученным конденсацией, п-салициловая альдегида с о-фенилен-диамина, изучены их антимикробные свойства.. Установлено, что синтезированные соединения представляют собой бис-л- ареновые комплексы, в координационную среду которых, включены атомы азота $\mathrm{C}=\mathrm{N}$-групп. Исследованы антимикробные свойства исходного азометина и его комплексов с медью и никелем. Показано, что в масле М-10 они проявляют высокую фунгицидную активность.

Ключевые слова: основания Шиффа, комплексы, активность, антимикробные свойства

\section{Abstract}

Synthesis of complexes of bivalent copper and nickel with Schiff base, condensation, p-salicylic aldehyde from o- phenylene diamine, and their antimicrobial properties have been studied. It has been established that the synthesized compounds are bis-p-arene complexes whose coordination medium, Nitrogen atoms of $\mathrm{C}=\mathrm{N}$ groups are included. The antimicrobial properties of the starting azomethine and its complexes with copper and nickel are investigated. It is shown that in oil M-10 they exhibit high fungicidal activity.

Keywords: Schiff bases, complexes, activity, antimicrobial properties 


\section{Введение}

Перспективные N-содержащие соединения представляют широкий класс органических хелатообразующих соединений, содержащих гетеро атомы. Такие соединения способны координировать с металлами, а полученные на их основе комплексы часто обладают эффективной биологической активностью.

Интерес, проявляемый в настоящее время к основаниям Шиффа, обусловлен тем, что они обладают определенным биологическим потенциалом [1-3]. Основания Шиффа, имеющие в своем составе гетеро атомы O, N, S способны к координации с металлами, а полученные на их основе комплексы проявляют биологическую и фунгицидную активность и характеризуются меньшей по сравнению с исходным лигандом токсичностью [4-5]. В этом плане, синтез и исследование координационных соединений переходных металлов с азометинами являются актуальными, как с научной, так и с практической точки зрения.

\section{Цель исследования,}

Целью исследования является синтез комплексов двухвалентного меди и никеля с Шиффовым основанием применяемые в. качестве многофункциональных присадок к смазочным маслам, улучшающие их антимикробные и износостойкостие свойства.

\section{Экспериментальная часть}

В представленной работе был осуществлен синтез комплексов $\mathrm{Cu} 2+$ и $\mathrm{Ni2+}$ с Шиффовым основанием, полученным конденсацией п-салицилового альдегида с о-фенилен-диамином и изучены их антимикробные свойства.

Синтез проводился с солями уксусной кислоты соответствующих металлов при мольном соотношении исходных реагентов 1:2 в этаноле:

$$
2 \mathrm{~L}+\mathrm{M}\left(\mathrm{CH}_{3} \mathrm{COO}\right)_{2} \mathrm{x} 4 \mathrm{H}_{2} \mathrm{O}=\mathrm{L}_{2} \mathrm{M}+2 \mathrm{CH}_{3} \mathrm{COOH} \text {. }
$$

где L- п-салицилиден-о-фенилен-диамина (1) $\mathrm{M}=\mathrm{Cu}$ (2); $\mathrm{Ni}$ (3).

В этих условиях реакция протекает легко и с достаточно высоким выходом $75 \%$ и $69 \%$ для меда и никеля, соответственно.

Поскольку результаты анализа колебаний с использованием значений ИКчастот и интерпретация полос поглощения в контексте со структурными данными позволяют получить информацию об участии отдельных атомов и фрагментов молекулы лиганда в координации с металлами [6]. 


\section{Результаты и их обсуждение}

Как известно из литературы, лиганды и их комплексы металлов являются значительно активными в отношении baccilus megaterium и Candida tropical, но влияние комплексов металлов сильнее, чем влияние лигандов. Известно также, что лиганды и их метал комплексы активны в отношении Fuherica Coli, Barilum sp и Pseudomanan acurtuginan. Кроме того, известно, что комплексы Си лигандов ингибируют активность против бактерий и грибков. Было также установлено, что лиганды могут оказывать ингибирующее действие на развитие Aspergillus niger, Penisilum rubium и Augergillus ferreus. Более того, было также установлено, что лиганды обладают антибактериальным и противогрибковым действием.

Функциональные свойства соединений изучались в масле M-8 с использованием стандартных лабораторных методов. Результаты изучения антимикробных и противоизносных свойств синтезированных соединений приведены в таблице 1.

Таблийа 1.

\begin{tabular}{|c|c|c|c|c|}
\hline \multirow{2}{*}{$\begin{array}{l}\text { Лиганды и } \\
\text { комплексы }\end{array}$} & \multirow{2}{*}{$\begin{array}{c}\text { Концентрац } \\
\text { ия, \% }\end{array}$} & \multicolumn{2}{|c|}{$\begin{array}{c}\text { Зона деградации } \\
\text { микроорганизмов,см }\end{array}$} & \multirow{2}{*}{$\begin{array}{c}\text { Зона деградации } \\
\text { микроорганизмов, } \\
\text { см }\end{array}$} \\
\hline & & $\begin{array}{c}\text { Смешанные } \\
\text { бактерии, } \\
\text { (МПА) } \\
\end{array}$ & $\begin{array}{c}\text { Смешанные } \\
\text { грибы } \\
\text { (СА) } \\
\end{array}$ & \\
\hline $\begin{array}{c}\mathrm{N}, \mathrm{N}-б и с- \\
\text { (диметиламинобензоил)д } \\
\text { иаминопропан }\end{array}$ & $\begin{array}{c}1.0 \\
0.5 \\
0.25\end{array}$ & $\begin{array}{l}3.0-3.0 \\
2.5-2.5 \\
2.3-2.3\end{array}$ & $\begin{array}{l}3.3-3.3 \\
2.4-2.4 \\
1.6-1.8\end{array}$ & 0.47 \\
\hline $\mathrm{L}_{2} \mathrm{CuX}{ }_{2}$ & $\begin{array}{c}1.0 \\
0.5 \\
0.25\end{array}$ & $\begin{array}{l}3.2-3.2 \\
2.6-2.6 \\
2.5-2.5\end{array}$ & $\begin{array}{l}3.2-3.2 \\
2.6-2.8 \\
2.0-2.0\end{array}$ & 0.4 \\
\hline $\mathrm{L}_{2} \mathrm{NiX}_{2}$ & $\begin{array}{c}1.0 \\
0.5 \\
0.25 \\
\end{array}$ & $\begin{array}{l}3.3-3.3 \\
2.6-2.6 \\
2.4-2.4\end{array}$ & $\begin{array}{l}3.0-3.0 \\
2.3-2.2 \\
2.1-2.1\end{array}$ & 0.45 \\
\hline $\begin{array}{c}\text { Пентахлорфенолят } \\
\text { натрия }\end{array}$ & $\begin{array}{l}1.0 \\
0.5\end{array}$ & $\begin{array}{l}1.3 \\
0.7\end{array}$ & $\begin{array}{l}1.4 \\
0.7\end{array}$ & \\
\hline Трикрезилфосфат & 1.0 & & & 0.65 \\
\hline Масло М-8 & - & ++ & ++ & \\
\hline
\end{tabular}

МПА-мясопентонный агар , а для грибов-сусло-агар - СА.

Как следует из таблицы, синтезированный азометин и его металлические комплексы обладают противомикробными свойствами. Они перебалансируют известную добавку пентахлорпрофенолата натрия (эталон) по эффективности (при тех же концентрациях).

В условиях синтезированного фрикционного режима, основания Шиффа и его комплексы с концентрацией $1 \%$, обладают высокими антимикробными 
свойствами $(0,47-0,40$ мм) и улучшают смазочные свойства нефти. Изученные добавки лучше известных присадок (трикрезилфосфат).

Противомикробную эффективность изученных соединений в масле М-8 оценивали по диаметрам зоны разложения вокруг полости, как с добавкой, так и без нее. Увеличение диаметров приводит к повышению эффективности противомикробных препаратов. Масло М-8 не обладает биостабильностью.

Анализ, публикуемых в настоящее время работ по синтезу и исследованию комплексов с переходными металлами показывает, что в большинстве случаев комплексные соединения биологически активны и обладают антимикробными свойствами. Представляет большой интерес, исследование влияния соединений 1-3 на биостойкость смазочных масел.

Антимикробные свойства определяли в составе смазочного масла М-10 в концентрациях $0,25-0,5 \%$. Эффективность антимикробного действия соединений 1-3 в качестве присадок, оценивалась по величине диаметра зоны угнетения роста бактерий и грибов вокруг лунки с присадкой и без нее: чем она больше, тем эффективнее антимикробное действие. Образцы, не пораженные микроорганизмами, считаются практически не подверженными микробиологическому повреждению. Масло М-10 не обладает биостойкостью.

$\mathrm{Cu}, \mathrm{Ni}$ (2-3) полученные на его основе, даже в малых концентрациях $(0,25$ $0,5 \%$ обладают фунгицидными свойствами в масле М-10. Кроме этого, соединения (1-3) не оказывают отрицательного влияния на физико-химические свойства масла М-10, что особенно важно для комплексов меди и никеля.

Аанализ полученных результатов позволяет утвердить, что синтезированные на основе азометина координационные соединения меди и никеля, представляют собой бис-л-ареновые комплексы, в координационную сферу которых включены оба атома азота $\mathrm{C}=\mathrm{N}$ групп.

Таким образом, синтезированные соединения представляют определенный интерес как многофункциональные добавки к смазочным маслам, улучшающие их противомикробные и противоизносные свойства. Использование их в композиции СОЖ позволит уменьшить количество компонентов при сохранении их эксплуатационных свойств. 
Синтезированные соединения с антимикробными свойствами изучались в композициях добавок к СОЖ. В композициях использовались известные промышленные добавки (S-75-детергент, многофункциональная добавка DF-11-

Выявлено, что как исходное Шиффовое основание, так и полученные комплексы (2-3) в смазочном масле М-10, проявляют себя как очень зффективные антимикробные присадки.

\section{Выводы}

1. Анализ полученных результатов позволяет утвердить, что синтезированные на основе азометина координационные соединения меди и никеля, представляют собой бис- $\pi$-ареновые комплексы, в координационную сферу которых включены оба атома азота $\mathrm{C}=\mathrm{N}$ групп

2. Установлено, что как исходное Шиффовое основание, так и полученные комплексы на основе меди и никеля в смазочном масле М-10, обладают высокими антимикробными свойствами (0,47-0,40 мм) и улучшают смазочные свойства нефти.

$* * *$

1. Shridhar Malladi, Arun M.Isloor, D.S.Akhila, Hooong-Kun Fun, arabian Journal of Chemistry(2013)6 335-340.

2. Laronze-Cochard Marie,Cochard Fabian,Daras Etienne, Lansiaux Amelie, Brassart Bertrand, Vanquelef Engueerran, and others Org and Biomol Chem 2010, 8, N20, Page 4625-4636, Engl.

3. Muhammed Ageel Ashraf, Karamat Mahmod, Abdul Wajid,Chemistry and Chemical Processing,IPCBEE, vol.10.(2011)IACSIT Press, Singapore.

4. Korany.A.Ali, Mokhles .M.Abd.Elzaher and Khaled Mahmoud,Hindawi Publishing Corporation,International Journal of Medicinal Chemistry, Vol2013,Article ID2568 ,36 pages.

5. A.M.Nassar, A.M.Hassan,A.N.Elkmasha and U.Z.Ahmed, International Journal of Chemical and Biochemical Sciences,IJCBS,2(2012), 83-93, ISSN2226-9614.

6. M.B.Fugu, N.R.Ndahi,B.B.Paul and A.N.Mustapha, Journal of Chemical and Pharmaceutical Research,2013,5(4);22-28,ISSN:0975-7384,CODEN(USA):JCPRC5.

7. Kavita Sharma Parveen, D.P.Singh and Rajan Copra // DuPharma Chemica, 2015, 7(2): $292-$ 300.

8. C.Justin, Dhanaraj and Jija Johnson, Synthesis applications new schiff bases derivatives // Research Journal of Chemical Sciences, vol 5 (4), 64-84, april (2015).

9. İmtiyaz Rassol Parrey and Athar Adil Hashmi Synthesis and biological evalution of schiff bases, // Canadian Chemical Transactions, 2015, volume 3 İssue 1, page 65-7. 